\title{
Segregación socio-espacial en una urbe turística de elite: El caso de Pucón, Chile
}

Socio-spatial Segregation in an Elite Touristic City: The Case of Pucón, Chile

Patricio Espinosa

Departamento de Antropología, Universidad Católica de Temuco, Chile

RESUMEN

El presente artículo da a conocer los resultados de una investigación cuyo objetivo fue caracterizar las distinciones del modelo de desarrollo territorial de la ciudad chilena de Pucón respecto de su asentamiento urbano. Utilizando una metodología cualitativa basada en entrevistas y revisión documental, se interpretó este fenómeno desde la teoría de sistemas sociales de Niklas Luhmann. Se concluyó que el asentamiento urbano segregado es comunicado como una permanente tensión entre la semántica del desarrollo territorial y la función del turismo local.

PALABRAS ClaVE: Turismo; Desarrollo; Segregación socio-espacial; Ciudad de Pucón; Sistemas sociales

ABSTRACT

This article discuss the results of a research focused on distinctions about the territorial development model of Chilean city Pucón as an urban settlement. By means of qualitative methodology based on interviews and documental review, this phenomenon was interpreted using Niklas Luhmann social systems theory. It was concluded that the segregated urban settlement is communicated as a permanent tension between the semantics of territorial development and the role of local tourism.

KEYWORDS: Tourism; Development; Socio-spatial segregation, Pucón city; Social systems

\section{INTRODUCCIÓN ${ }^{1}$}

Pucón, comuna ubicada en la provincia de Cautín, región de La Araucanía, Chile, es un destino turístico consolidado, con alta afluencia de visitantes en temporada estival e invernal. A su haber cuenta con variados atractivos naturales que lo hacen único en el contexto regional y nacional. Destacan sus aguas termales y balnearios lacustres; también sus parques nacionales y su particular centro de esquí, el que se emplaza en un volcán activo (volcán Villarrica). Igualmente sobresalen, y de manera particular, sus diversos servicios hoteleros, los que se orientan a segmentos sociales con altos ingresos económicos y constituyen el principal paisaje urbano de

\footnotetext{
${ }^{1}$ Este artículo ha sido financiado por la Dirección General de Investigación y Postgrado de la Universidad Católica de Temuco, proyecto: "Escritura, antropología y reflexión científica", CDP-CDP2014-06

REVISTA MAD - REVISTA DEL MAGÍSTER EN ANÁLISIS SISTÉMICO APLICADO A LA SOCIEDAD ISSN 0718-0527

Facultad de Ciencias Sociales, Departamento de Antropología.

Universidad de Chile

www.revistamad.uchile.cl
}

DOI: http://dx.doi.org/10.5354/0718-0527.2016.40619 
Pucón (Hidalgo \& Zunino 2012). La ciudad misma se configura como ciudad fachada, esto es, una ciudad que se planifica para hacerse deseable a la visita turística (Aragón 2013). Todo ello se acompaña con un particular patrimonio cultural producto de la presencia de población mapuche, vestigios hispánicos del siglo XVI y las migraciones de colonos europeos a comienzos del siglo XX. Sin embargo, esta urbe posee en sus márgenes diversos conjuntos de viviendas sociales que se erigieron desde la década de 1970 como medida del Estado frente a las sostenidas tasas de inmigración campo-ciudad con escasa capacidad de pago. Conforme avanzaron las décadas, la periferia urbana creció y se consolidó en torno a las viviendas sociales, las que se caracterizan por su fragilidad estructural y carencias materiales (Zunino, Hidalgo \& Marquardt 2011). Hasta el año 2006 se edificaron un total de doce poblaciones con viviendas sociales, las cuales se distribuyen a lo largo y ancho de la periferia urbana. Quienes las habitan pertenecen a estratos socioeconómicos bajos y provienen en su mayoría del sector rural de la misma comuna. Se trata de poblaciones segregadas socio-espacialmente del Pucón turístico, lo cual lleva a que el paisaje urbano de Pucón sea altamente contrastante si se atiende a la distribución del espacio. Mientras al casco urbano es depositario de la semántica turística a través de sus atractivos (servicios, balneario, patrimonio y arquitectura), los conjuntos poblacionales de las márgenes permanecen segregadas, en las antípodas de la comunicación turística local.

Se propone en el presente trabajo que la segregación socio-espacial en Pucón posee características particulares que deben ser analizadas en función del concepto de turismo y de la semántica del desarrollo territorial local. Se sostiene que dichas características van más allá del contraste material entre el atractivo turístico y la segregación propiamente tales, toda vez que en el contexto se observan dinámicas de inclusión/exclusión de la población segregada. Para ello, se aplica la teoría de sistemas sociales (Luhmann 1991) a fin de encontrar en ella el rendimiento teórico que permita caracterizar tanto al turismo como a la semántica del desarrollo, para luego comprender el fenómeno de la segregación socioespacial de Pucón a través del primado de ambos conceptos.

Para la teoría de sistemas sociales el único elemento estrictamente social, y por ende susceptible de ser observado, es la comunicación (Luhmann 1991). Plantea además que la sociedad contemporánea se caracteriza por la diferenciación funcional, esto es, un logro evolutivo que conduce a que los problemas emerjan y se atiendan a través de sistemas 
funcionales especializados y autónomos, como el sistema económico que se ocupa del problema de la escasez, el sistema político ocupado del decidir colectivamente o el sistema de la ciencia que se ocupa del problema de la construcción de conocimiento. Los sistemas funcionales procesan sentido a través de su propia codificación binaria (Luhmann 2007) que duplica al mundo entre un valor positivo y otro negativo, como el pagar o no pagar para el sistema económico, el poder/ no poder (gobierno/ oposición) para el sistema político y la verdad/ no verdad para el sistema de la ciencia. En otros términos, toda observación efectuada por los sistemas funcionales es realizada mediante su respectivo código y se difunde mediante medios de comunicación simbólicamente generalizados o comunicación dominante de cada sistema.

Señaladas estas características, y siguiendo a Farías (2008), se caracteriza al turismo como medio de comunicación (Luhmann 2007) cuya función es la probabilización del viaje de ocio. Los medios de comunicación en la teoría de sistemas sociales tienen la función de hacer probable la comunicación en situaciones de alta improbabilidad. De este modo, comprender al turismo como medio permite que su función sea reconocible y susceptible de ser procesada por la comunicación sistémica. Ello permite la escisión de consideraciones ligadas exclusivamente a la dimensión objetual para su comprensión, otorgando apertura a la dimensión social y temporal; en conjunto, las dimensiones del sentido (Luhmann 2007). Por su parte, se entenderá al concepto de desarrollo como una forma de autoobservación de la sociedad, cuya principal característica es transferir al futuro la posibilidad de comprender su propia estructura y leer sus problemáticas. Ello debido a que, como hemos señalado, en la sociedad contemporánea, o funcionalmente diferenciada, cada sistema observa y procesa sentido de acuerdo con sus propias y autorreferentes operaciones, por lo que no es posible observar una problemática de manera unívoca. Siguiendo a Niklas Luhmann (1997), esta imposibilidad puede ser rastreada hacia fines del siglo XVIII, época en la cual la sociedad ya no puede comprender la estructura de sus operaciones sólo desde un centro. Es allí donde emergen conceptos como 'modernidad' y 'progreso' abrazando precisamente la idea de futuro. De este modo, el concepto de desarrollo puede observarse como una semántica promisoria y comprensiva de la sociedad al llevar al futuro tanto la posibilidad de obtención de mejores estándares de vida como de comprensión de las paradojas y dilemas sociales. En el caso de estudio que se presenta a continuación, el modelo de desarrollo local toma como 
la principal competencia territorial al medio turismo, vale decir, al turismo como eje dinamizador de la comunicación promisoria y comprensiva de lo local. Con todo, esta base teórica y conceptual permitirá caracterizar la construcción turística de Pucón, desde sus albores hasta nuestros días, y asimismo comprender la segregación socio-espacial como una paradoja suscitada en el modelo de desarrollo territorial turístico de Pucón.

El trabajo inicia presentando los principales elementos metodológicos de la investigación para luego reflexionar en torno al lugar del modelo de desarrollo territorial comunal de Pucón, el cual es observado como un programa decisional perteneciente al propio gobierno comunal. A continuación, se discute la emergencia, crecimiento y consolidación del turismo en Pucón, proponiéndose dos esquemas de observación: el primero respecto de las semánticas que han acompañado su evolución territorial, y el segundo en torno de la instalación de atractivos turísticos. Posteriormente se caracteriza la construcción turística de Pucón siguiendo el primado de sus atractivos, los que se asocian a determinados perfiles sociales para, enseguida, caracterizar la distinción del modelo de desarrollo territorial turístico respecto del asentamiento urbano segregado como lado excluido del atractivo. Finalmente, se presentan las principales conclusiones.

\section{METOdOLOGÍA}

Se accedió al problema de investigación a través de un diseño de carácter descriptivo con una metodología eminentemente cualitativa, la cual contempló análisis de fuentes primarias y secundarias. En lo que respecta a las fuentes primarias, se efectuaron un total de 6 entrevistas a directivos de programas de la Municipalidad de Pucón, en el periodo comprendido entre los días 05 de septiembre de 2013 y 10 de abril de 2014, los cuales estaban directamente vinculados con la planificación territorial. Para ello se construyó un guion de entrevista semiestructurado orientado por temas atingentes a los objetivos propuestos. Las fuentes secundarias se extrajeron a partir de Planes y Programas municipales tomando como eje temporal el periodo en que se inscribe el Plan de Desarrollo Comunal de Pucón (2010-2014). Con los datos obtenidos se analizaron las distinciones respecto del asentamiento urbano segregado de Pucón presentes en el modelo de desarrollo territorial. Para ello, se caracterizaron los esquemas de distinción de la unidad muestral para identificar aquellos ámbitos incluidos y excluidos en la comunicación turística hacia el territorio 
urbano, y a partir de allí, se observó el rol del asentamiento urbano segregado de Pucón en la construcción del Pucón turístico. Motivó en el presente estudio el comprender cómo se regula y/o normaliza la segregación territorial desde la comunicación turística local.

2. GOBieRno COMUNAL DE PUCÓN COMO SISTEMA ORGANIZACIONAL: EL LUGAR DEL MODELO DE DESARROLLO TERRITORIAL

El concepto de desarrollo comunica un futuro promisorio y comprensivo a la sociedad, lo que ha llevado a que, en general, su semántica se asocie al aumento de estándares de calidad de vida (Boisier 2007; González 2013; Violá 2000). Un modelo de desarrollo territorial puede comprenderse como aquel programa mediante el cual se establecen criterios de sentido local a la propia semántica del desarrollo. Acá se puede encontrar la definición e implementación de competencias territoriales, la distinción de las principales problemáticas sociales y las estrategias mediante las cuales dichas competencias permiten el tratamiento de los problemas locales. Así, el lenguaje de un modelo de desarrollo territorial integra a la población que se circunscribe a su área de competencia. De este modo, aquel futuro promisorio y comprensivo programado en torno a una competencia territorial se conecta con el "principio de legitimidad" (Torres Nafarrate 2009: 183), el cual sólo se sostiene a través de decisiones colectivamente vinculantes. Para Javier Torres Nafarrate, el principio de legitimidad comparte sentido con el "principio del bien común", siendo establecido por el sistema de la política a través de procedimientos que permiten tratar la contingencia abierta a través de estructuras simbólicas que median entre las operaciones del sistema y su entorno. Estas estructuras son las fórmulas de contingencia:

(Su) función consiste en rebasar el límite entre determinación e indeterminación y para ello recurren a factores históricamente dados. Las fórmulas de contingencia hacen observable lo que no es observable desde el momento en que una unidad sustituye a la diferencia (Torres Nafarrate 2009: 180).

Con ello, es posible obtener que la articulación de un modelo de desarrollo territorial se corresponde con la recursividad del sistema político y, además, que el medio turismo es observado como fórmula de contingencia. Esto implica que la tematización política del turismo (como la principal competencia de un modelo de desarrollo territorial) puede 
desencadenar perturbaciones en el entorno al dejar en evidencia el carácter contingente de dicha tematización. De ello se obtiene que esta competencia pudo haber sido otra, sobre todo si se presta atención (como veremos más adelante) a cómo se resuelve la presencia de un contexto socio-espacial segregado en un enclave turístico de tradición elitista. De este modo, situar al turismo como fórmula de contingencia implica que un modelo de desarrollo territorial turístico es la manera en que el sistema político, para el presente caso observado desde un gobierno comunal, absorbe la complejidad de su entorno.

Un gobierno comunal, o municipio, se entenderá como un sistema organizacional (Arnold 2008), el cual toma para sí el programa y código del sistema de la política, emergiendo fruto de la segmentación del Estado en tanto órgano al que le está asignada la "responsabilidad total de la política para una región determinada" (Torres Nafarrate 2009: 272). Un sistema organizacional se caracteriza por enlazar comunicaciones en forma de decisiones (Luhmann 2005; Arnold 2008). Las decisiones son distinciones de alternativas que permiten al sistema organizacional absorber incertidumbre separando al mundo entre un antes y un después (Luhmann 2010). El antes en la forma de la decisión define contingencia abierta, el punto en que gran parte todavía puede ser cambiado ante la latencia de diversas posibilidades. El después plantea contingencia fija en relación a la posibilidad de haber alcanzado una decisión diferente (Andersen 2001). No obstante, su naturaleza contingente, la decisión obliga al sistema organizacional a generar nuevas selecciones mediante nuevas decisiones, incrementando así la complejidad (Luhmann 2005). Siguiendo esta lógica, un gobierno comunal constituye los problemas de su entorno a través de sus propias operaciones recursivas, esto es, desde su propia autorreferencialidad. Para ello, establece un problema a tratar, delimitando y especificando metas para posteriormente establecer un programa de tareas para alcanzar dichas metas. Este mecanismo da el vamos al complejo proceso recursivo mediante el cual el sistema organizacional gobierno comunal se da a la tarea de su función: el establecimiento de decisiones colectivamente vinculantes circunscritas a su territorio de competencia.

La construcción de un modelo de desarrollo territorial se basa en la distinción del entorno de acuerdo con la 'correcta' (legítima) operación decisional. Por ello, la articulación de este programa decisional a través del medio turismo responde a la configuración de estructuras resultantes de decisiones ya tomadas que distinguieron en este medio la posibilidad de 
establecer nuevas decisiones para el tratamiento de las problemáticas del territorio, el cual, a través de la semántica del desarrollo territorial, pone énfasis en la comunicación de un futuro prometedor capaz de aprehender la complejidad local. Se ve, pues, que la naturaleza de las operaciones recursivas, en el marco de la construcción de un modelo de desarrollo, son paradójicas, pues la absorción de incertidumbre por parte del sistema organizacional ocurre sólo porque el futuro es desconocido. El futuro no es alcanzable, por ello la decisión no permite al sistema más que operaciones osciladoras respecto del tiempo (Luhmann 2010). De manera tal, un modelo de desarrollo territorial en ningún caso puede pretender seguridad plena respecto del futuro y de su entorno por la naturaleza recursiva de las operaciones antes descritas. Pensar, entonces, en llevar el 'destino de un territorio' implica que un modelo de desarrollo territorial se corresponde con decisiones que llevan al sistema a decidir y a establecer expectativas respecto de su entorno. Por ello, el empleo del medio turismo como fórmula de contingencia al decidir, significa que el sistema lo privilegia en el tratamiento de la incertidumbre para disponer de fórmulas de cálculo de riesgo, o "atribuciones causales" (Torres Nafarrate 2009: 398) que ayuden a descomplejizar el entorno y así efectuar la apuesta por el futuro. De este modo, la emergencia del medio turismo como fórmula de contingencia para el decidir del sistema se fundamenta bajo criterios que le otorgan legitimidad en el tratamiento de la complejidad del entorno. Puede suponerse del gobierno comunal una observación como la que sigue: en la medida que el territorio en pleno contribuya a probabilizar el viaje de ocio está además contribuyéndose a sí mismo.

\section{GÉNESIS Y DESARROLLO TURÍSTICO EN PUCÓN}

La fundación de Pucón fue antecedida en semanas por la refundación de la vecina comuna de Villarrica, conocida como el último bastión de la resistencia del pueblo mapuche frente al Estado chileno (Bengoa 2000). Pucón fue fundada el 27 de febrero de 1883 como reducto militar estratégico en las postrimerías de la Pacificación de La Araucanía, campaña de ocupación militar en territorio mapuche llevada a cabo entre los años 1861 y 1883. Hacia mediados del siglo XIX la República de Chile había postergado sus intereses territoriales en La Araucanía, relegando su vínculo a misioneros cristianos y comerciantes. En este periodo llega el primer grupo de colonos europeos a las zonas de Valdivia, Llanquihue, Osorno y Puerto Montt. Posterior a ello, el Presidente Bulnes ocupa la 
zona austral, desarrollándose a los pocos años la industria ganadera ovina. El único territorio del sur que para entonces no había sido incorporado a la República de Chile era La Araucanía, una incorporación que buscando expandir los territorios agrícolas y ganaderos nacionales se justificó bajo la narrativa de la terra nullius, literalmente 'tierra de nadie', aludiendo ya sea a una ausencia de población o a bárbaros sin derechos de pertenencia territorial (CEPAL 2014). En consecuencia, los nuevos asentamientos de La Araucanía se forjaron mediante semánticas que los vinculaban a zonas fronterizas, desconocidas y hostiles. Ello motivó ágiles políticas de ocupación basadas en actividades extractivas, lo que atrajo a un importante contingente de especuladores e inversionistas privados (Pinto 2003).

La principal fuente productiva en Pucón a los pocos años de su fundación fueron los recursos forestales. Pucón abastecía la creciente demanda maderera de la región y del país, expoliándose numerosos bosques nativos (Zúñiga 2011). Esta zona aún no se distinguía como atractivo turístico, era simplemente un reservorio maderero, ganadero y una ruta estratégica hacia la fronteriza República Argentina. A comienzos del siglo XX arriban a Pucón los primeros colonos europeos, quienes crearon buena parte de los primeros hospedajes y servicios de alimentación dadas las dinámicas sociales motivadas por la industria maderera y el tráfico por los pasos fronterizos. No obstante, el Estado esperaba otro tipo de lógica productiva respecto del colono en la región. En estos cifraba apuestas por la transformación de La Araucanía en una potencia agrícola industrial, lo que finalmente fracasó. En su defecto, los colonos "abandonan rápidamente sus hijuelas para dedicarse al comercio, instalar negocios, hoteles o simplemente dedicarse a sus antiguos oficios en los pueblos y ciudades" (Bengoa 2000: 353). Justamente los colonos europeos asentados en Pucón siguieron este patrón productivo, destacándose en la construcción de hoteles en lo que actualmente es el caso urbano de la ciudad. Así, la naturaleza del asentamiento urbano en Pucón se orientó en función del aprovechamiento de la rivera del lago Villarrica con los primeros hoteles: Hotel Geis en 1915, Hotel La Posada en 1918, Hotel Acevedo en 1919 entre los más antiguos (Contreras 2008).

En el año 1935 Pucón será testigo del más importante impulso hacia el turismo. En aquel año se inaugura el Gran Hotel Pucón, construcción financiada por el Programa de Construcción de Hoteles de Ferrocarriles del Estado que justamente es inaugurado en esta zona. El Gran Hotel Pucón se convierte en uno de los mayores hoteles del país, contribuyendo 
"a la domesticación de un paisaje que poco antes había sido considerado como espacio impenetrable e indómito" (Booth \& Lavín 2013: 58).

El decisivo rol infraestructural de Ferrocarriles del Estado fue acompañado por la creación de revistas turísticas editadas por la misma empresa. Entre ellas se cuentan revista 'En Viaje' de 1933, y la 'Guía del Veraneante' de 1934, las que ciertamente ayudaron a crear las imágenes que hasta el día de hoy imperan respecto del sur de Chile. Así, la instalación de la semántica del atractivo al sur de Chile obedeció a políticas de integración nacional que reconocieron en el entorno natural elementos susceptibles de renovar la imagen que se forjó al alero de la Pacificación. Un territorio, otrora ocupado por la 'antítesis de la civilización', se convierte en una promisoria fuente productiva. Pucón comienza a ser comunicado mediante la estética del atractivo natural, incorporándose así a las imágenes identitarias de la nación.

PUCÓN, en medio de una naturaleza bravía y generosa, tiene un destino fulgurante. Surgido, como un sueño de hadas, en un ambiente de secular majestad, pone en el panorama autóctono la gracia de su arquitectura y su silueta emerge del fondo verdinegro de los bosques como la realización acabada y sutil de una obra de magia. (Revista En Viaje 1940: 18)

No obstante, la pionera actividad hotelera de los colonos europeos, lo cierto es que, al alero del programa de construcción de hoteles de Ferrocarriles del Estado, Pucón es finalmente impulsado hacia la consolidación de un modelo de desarrollo territorial fundado en el turismo. Su abundante y variada riqueza natural permitió que comenzase a ser reconocido como destino turístico, incluso a nivel internacional (Contreras 2008), además de contribuir a modificar la imagen nacional de La Araucanía. Cabe destacar que este impulso estatal para la instalación de la semántica turística en Pucón obedeció además a un cambio generalizado en la estructura económico-productiva del país. La impronta liberal con que se desarrollaba la industria nacional desde fines del siglo XIX comenzó a modificarse con una mayor y sostenida participación estatal hacia la década de 1920. Con la Primera Guerra Mundial, Chile fue ampliamente favorecido por la altísima demanda de salitre, y a su vez, empujado a desarrollar el mercado interno a raíz del encarecimiento de las importaciones. Ello impulsó una mayor diversificación y crecimiento de la industria manufacturera. Pero con la violenta caída del precio de salitre, el modelo económico productivo, que hasta entonces había sido dejado en manos de particulares, es ahora asumido por el Estado, gestándose 
nuevos enclaves comerciales e industriales bajo la consigna de fortalecer el mercado interno que, paralelamente, fue orientado por robustos procesos de urbanización (Geisse \& Valdivia 1978). El impulso estatal del turismo en Pucón fue una expresión industrial de esta renovada orientación económica, la que, a su vez, puede observarse como un mecanismo político de apropiación que permitió al Estado hacerse de un territorio cuya ocupación había sido postergada hasta la segunda mitad del siglo XIX. Asimismo, la semántica del atractivo natural, exaltada mediante importantes inversiones estatales en la zona, instaló en La Araucanía la imagen de una selva virgen bella y exuberante.

CUAdRo 1: LA CONSTRUCCIÓN SOCIO-PRODUCTIVA DE Pucón HACIA LA PRIMERA MitAD DEL SIGLO XX

\begin{tabular}{|c|c|c|}
\hline Periodo & Mecanismo & Semántica \\
\hline $1861-1883$ & $\begin{array}{c}\text { Pacificación de La } \\
\text { Araucanía }\end{array}$ & Terra nullius \\
\hline $1883-1925$ (aprox.) & Economía extractiva & $\begin{array}{c}\text { Reservorio maderero, paso } \\
\text { fronterizo }\end{array}$ \\
\hline 1930 & Turismo & Belleza natural, virginidad \\
\hline
\end{tabular}

FUENTE: Elaboración propia

Como se desprende del Cuadro 1, el empleo del medio turismo en la construcción socioproductiva de Pucón se ubica a partir de la década de 1930. La instalación del imaginario social que distingue a Pucón como un territorio de belleza natural, exuberante y singular perdura incluso hasta nuestros días, siendo las posteriores décadas testigos de la profundización y la especificación de sus atractivos. Desde sus primeras décadas como destino turístico, Pucón fue conocido como un paraíso de la pesca, concitando la visita de célebres personajes de la política y el arte internacional (Contreras 2008). Iniciándose la década de 1970 el número de visitantes comienza a incrementarse gracias a la pavimentación de diversas rutas interiores. A fines de la década de 1980, con la realización de la primera competencia 'Ironman Pucón' (1988), se instala el deporte como criterio de innovación turístico, generándose diversos servicios y emprendimientos privados orientados a la práctica deportiva. En 1990 abre el Casino de Juegos de Pucón, y con él un nuevo derrotero turístico ligado al lujo y las apuestas. En 1999 y 2000 se instalan La Universidad de la Frontera sede Pucón y el Instituto Eurochileno de Turismo respectivamente, contribuyendo a la formación de capital humano turístico. Más recientemente, en el año 2007, el Servicio Nacional de 
Turismo establece un convenio de trabajo con la Corporación Nacional de Desarrollo Indígena para mejorar y promover la oferta de turismo mapuche en la región de La Araucanía. En el año 2010 se publica el 'Plan Araucanía 7' (Gobierno de Chile 2010), un programa de acciones estratégicas para el desarrollo de la región. Este comprendió diversos ejes de trabajo, dentro de los cuales es posible observar un especial énfasis en el turismo. Entre las acciones que promovía el Plan se cuentan la exaltación de elementos etnológicos mapuche para el desarrollo turístico de La Araucanía, el establecimiento de rutas turísticas étnicas y un plan de construcción y posicionamiento de una imagen regional (Gobierno de Chile 2011). En este marco surge el eslogan 'Araucanía Naturaleza Originaria' para promocionar a la región (Bertin 2013).

Inspirado en estos instrumentos de planificación, el gobierno comunal de Pucón comienza a tematizar la cultura mapuche como atractivo turístico. Dicha tematización pone sus énfasis en la protección y exhibición del patrimonio cultural mapuche, planteando su participación como atractivo en el turismo local en tanto forma de vida superviviente. De igual modo, observa al turismo como el conducto ideal entre conservación patrimonial y oportunidad económica para la población mapuche, relación fuertemente asociada al turismo indígena como fenómeno mundial (Butler \& Hinch 2007).

CUAdro 2: EVOLUCiÓN TURÍsTiCA DE PUCÓN

\begin{tabular}{|c|c|c|c|}
\hline Periodo & Elemento & Atractivo & Semántica \\
\hline 1930 & Naturaleza & Paisaje & $\begin{array}{c}\text { Circuito fluvial - destino } \\
\text { lacustre }\end{array}$ \\
\hline 1980 & Naturaleza & Deporte & Deporte - aventura \\
\hline 1990 & Turismo de Lujo & Casino de juegos & Lujo - bohemia \\
\hline 2000 & Educación & $\begin{array}{c}\text { Servicio } \\
\text { profesionalizado }\end{array}$ & $\begin{array}{c}\text { Turismo disciplinario - } \\
\text { profesional }\end{array}$ \\
\hline 2010 & Cultura & Pueblo mapuche & $\begin{array}{c}\text { Destino turístico } \\
\text { indígena }\end{array}$ \\
\hline
\end{tabular}

FUENTE: ELABORACIÓN PROPIA

En síntesis, la construcción turística de Pucón se inicia hacia la década de 1930 fruto de iniciativas privadas y políticas sociales que buscaban convertir a Pucón en un destino turístico enlazando al entorno natural como el principal atractivo. Estas acciones se vieron reflejadas en el levantamiento de diversos hoteles que hoy orientan su particular 
arquitectura urbana. Conforme avanzaron las décadas, es posible observar distintos atractivos que cristalizan en lo que hoy es el Pucón turístico.

\section{LA CONSTRUCCIÓN TURÍSTICA DE PUCÓN: ENTRE ATRACTIVOS Y SUJETOS DEL} TURISMO

Para el gobierno comunal de Pucón el turismo representa el eje estratégico basal en su política de planificación territorial. De igual manera, es el concepto con el cual traza su modelo de desarrollo territorial (Municipalidad de Pucón 2010a: 133). La conversión del espacio en atractivo turístico en Pucón sigue una lógica de enlace basada en cuatro criterios fundamentales (Cuadro 2): la naturaleza, el turismo de lujo, la profesionalización del servicio y la cultura. El primero de ellos, la naturaleza, es el que se ha heredado desde la génesis del turismo local. La semántica de un territorio de exuberante y virginal belleza persiste con fuerza en la actualidad y es enrolado como el principal capital económico de la comuna:

Pucón cuenta con una cantidad de recursos naturales y servicios turísticos alrededor de la zona urbana muy fuertes, muy potentes, que tienen calidad diferenciadora sobre otros productos similares. Por ejemplo, rafting existe en otros puntos de Chile, pero es reconocido que Pucón es la capital del rafting y del turismo aventura a nivel nacional (Funcionario municipal 1)

El turismo de lujo, por su parte, otorga a Pucón un distintivo del resto de las comunas de La Araucanía. El lujo otorga un criterio de inclusión/exclusión de turistas que decanta en que tanto infraestructura como servicios asociados apunten a segmentos sociales de alto poder adquisitivo. Una de las características más reconocidas del turismo en Pucón es su exclusividad, la que se construye en un doble sentido: exclusividad de atractivos y exclusividad en el visitante objetivo:

Tú no puedes prohibirle a la gente el turismo, pero si tú cobras más es menos la gente que puede pagar para verlo, así tú generas la misma cantidad de ingresos para Pucón, pero con menos gente, con menos presión para el medioambiente [...] Acá en Pucón decimos que un árbol vivo vale más que un árbol muerto, porque a un árbol vivo se pueden llevar a muchos turistas durante muchos años a ver ese árbol, y cada turista genera un ingreso. Un árbol muerto se puede vender solo una vez. (Funcionario municipal 1) 
Por otro lado, la oferta de una educación turística en Pucón responde a la sensibilidad del sistema educativo por la estructura económicoproductiva del entorno. Mediante este tipo de educación, se entregan conocimientos técnico-profesionales que contribuyen a hacer de Pucón un destino turístico con servicios diferenciados en cuanto a su alta calidad y elevado nivel de profesionalismo. La profesionalización de servicios turísticos, por ende, es igualmente enlazada como atractivo en tanto tributa a la probabilización del viaje de ocio.

Las poblaciones de nosotros tienen una ubicación estratégica, donde la mayor mano de obra local, en todos los rubros del turismo, se provee de estas poblaciones. Allí existen muchas familias trabajadoras que se han ido especializando; y muchos ya, prácticamente por toda la capacitación que existe acá $[. .$.$] hacen una contribución en mano de obra a la industria (Funcionario$ municipal 2)

Por su parte, la cultura se refiere a la conversión en atractivo del mundo mapuche, ámbito que ha cobrado alta relevancia en los últimos años en Pucón.

Esta comuna tiene un importante porcentaje de personas descendientes de la sangre mapuche, y de una u otra forma el rescate cultural de ellos ha permitido reforzar nuestro destino turístico con un sello inclusivo y apegado a la matriz indígena, que es de alto interés por ejemplo para el turista extranjero. (Funcionario municipal 3)

Cabe destacar que la conversión del espacio en atractivos por parte del gobierno comunal implica a su vez la construcción de una serie de sujetos sociales implicados directamente en la semántica turística. A estos les hemos denominado 'sujetos del turismo', esto es, sujetos con funciones específicas asociadas a los atractivos en sintonía con el modelo de desarrollo territorial. La construcción de estos sujetos se efectúa en el seno de los atractivos locales, dentro de los cuales encontramos al empresario, quién poseería la facultad de intervenir la naturaleza a través de sus planes de negocios; al turista, de quién se espera un determinado nivel de gasto correspondiente con un tipo de perfil socioeconómico; al residente joven, que se sentiría atraído por incluirse en la semántica turística por medio de la educación; y al residente mapuche, quien permitiría nuevos derroteros turísticos mediante la conversión de su estilo de vida en atractivo. Estos son los sujetos que se incluyen en el medio 
turístico local, es decir, son quienes construyen a Pucón como destino turístico.

CUADRO 3: LOS SUJETOS DEL TURISMO EN PUCÓN

\begin{tabular}{|c|c|c|}
\hline Atractivo & Sujeto & Expectativa/función \\
\hline Naturaleza & Empresario & Interventor \\
\hline Turismo de Lujo & Turista & Consumidor \\
\hline $\begin{array}{c}\text { Servicio } \\
\text { profesionalizado }\end{array}$ & Residentes jóvenes & $\begin{array}{c}\text { Técnicos/profesionales del } \\
\text { turismo }\end{array}$ \\
\hline Cultura & Residentes mapuche & Atractivo \\
\hline
\end{tabular}

FUENTE: Elaboración propia

Como se observa en el Cuadro 3, son fundamentalmente tres los sujetos turísticos cuyo rol se asocia a probabilizar el viaje de ocio: el empresario, el residente joven y el mapuche. La evolución en la construcción turística de Pucón decanta en la instalación de esta triada de sujetos que representan un perfil social en correlato con la semántica turística local, y cuyas funciones se orientan según el atractivo al cual se vinculan. Esto implica que a través del medio turismo se contemple exclusivamente en estos perfiles la posibilidad de innovación de las competencias turísticas del territorio. Así, la comunicación turística en Pucón excluye a los sujetos que justamente no se corresponden con este perfil, tornándose indiferente respecto de aquellos en la medida en que sus funciones no se asocian a probabilizar el viaje de ocio. Sin embargo, a la indiferencia de la comunicación turística por un entorno no funcional al turismo se contrapone su inclusión por parte de la semántica del desarrollo; vale decir, si para el turismo son solo relevantes cierto tipo de espacios y de sujetos, la semántica del desarrollo territorial en Pucón emerge precisamente para incluir la dimensión excluida del medio turismo. Cobra fuerza pues la paradoja que se instala a partir de la pregunta de investigación señalada, pues se trata de una interrogante que invita a observar el asentamiento urbano segregado como una construcción de sentido suscitado en el seno de la relación entre turismo y desarrollo territorial.

\section{ASENTAMIENTO URBANO SEGREGADO COMO LADO EXCLUIDO DEL ATRACTIVO}

Como se ha señalado, la semántica del desarrollo se sostiene como comunicación de futuro que trae consigo la promesa de bienestar y la 
posibilidad de asir la complejidad de la sociedad. Esto se ha sintetizado como semántica promisoria y comprensiva, semántica que para el contexto observado se procesa a través del medio turismo. Esto implica que el territorio se distingue mediante la generalización simbólica del atractivo, estableciéndose con ello elementos territoriales que permiten y no permiten probabilizar el viaje de ocio.

La naturaleza, el turismo de lujo, la cultura y el servicio profesionalizado son los atractivos mediante los cuales se actualiza la comunicación turística en Pucón. En este entendido, el asentamiento urbano segregado, como expresión social y espacial precaria que no ofrece elementos susceptibles de probabilizar el viaje de ocio, no participa en la comunicación turística local. No obstante, sí lo hace en la semántica del desarrollo territorial ya que esta no establece criterios de exclusión respecto de la población, como si lo hace el medio turismo. Por ello, el asentamiento urbano segregado, como expresión social y espacial precaria, sí participa en la promesa y comprensión transferida al futuro y movilizada por el medio turismo. Así, el asentamiento urbano segregado es incluido en el modelo de desarrollo territorial turístico como el "lado no marcado" (Spencer-Brown 1972) de la comunicación turística local. Para observar cómo es distinguido el asentamiento urbano segregado desde el gobierno comunal, la propuesta es ubicar el foco en el lado no marcado del atractivo, y desde ahí observar cómo es procesada la segregación socio-espacial en tanto lado excluido de la comunicación turística local.

\section{ATRACTIVO NATURALEZA}

La naturaleza es reconocida como el atractivo más importante de Pucón, siendo caracterizada fundamentalmente como paisaje de lago y montaña propicia para actividades de época estival e invernal. También es descrita como atractivo altamente vulnerable de no mediar especiales cuidados para su preservación (Municipalidad de Pucón 2010a). Como se puede observar en el Cuadro 3, la posibilidad de intervenir este atractivo recae en el sujeto empresario, por lo que otros sujetos residentes están supeditados a su cuidado y a reconocerla como el principal sostén económico de la comuna. Estos últimos, en consecuencia, son distinguidos como agentes de preservación o degradación de este atractivo (Municipalidad de Pucón 2011b). 
Nuestro medioambiente es nuestro capital de trabajo. Cuando hablamos de capital de trabajo, hablamos de palabras mayores. Ya no es simplemente un bosque o un parque. Es nuestro bien, bienes que nosotros aprovechamos para generar riqueza. Entonces, [...] desde el Alcalde de Pucón hasta la gente que recibe de forma indirecta los beneficios del turismo hablan de que, claro, nuestro ADN está en el turismo. (Funcionario municipal 1)

Esta distinción guarda directa relación con una lógica que establece una red de expectativas orientadas al reconocimiento y resguardo del principal atractivo turístico de la comuna. De aquí se desprende la aplicación de un criterio eminentemente moral (Luhmann 2013), que invita a la población segregada a limitar sus posibilidades de acción con este atractivo: lo apropiado (bueno) sería aquel comportamiento que se ajuste a reconocer en el turismo el principal camino del desarrollo territorial, y particularmente al atractivo naturaleza como un elemento altamente sensible a la presencia humana. Lo inapropiado (malo) sería desconocer al turismo como el principal camino del desarrollo territorial y a la naturaleza local como un atractivo altamente sensible a la presencia humana. De este modo, podemos hablar en este punto de una ética turística resultante de la distinción reflexiva del código de la moral (bueno/malo) aplicado a la población segregada, y así, de un asentamiento urbano segregado que, observado desde el primado del atractivo naturaleza, es incluido solo en tanto se le distingue desde una ética turística.

\section{ATRACTIVO SERVICIO PROFESIONALIZADO}

La educación turística es el mecanismo mediante el cual se introduce la profesionalización en la comunicación turística local. Sumada a la oferta en educación turística disponible en la Universidad y Centro de Formación Técnica presentes en Pucón (Universidad de la Frontera sede Pucón, Instituto Eurochileno de Turismo), se encuentra la Política de Educación Municipal denominada "Educar para innovar y emprender 2010-2016" (Municipalidad de Pucón 2010c). Esta política se compone de cuatro programas orientados a fortalecer el aprendizaje y a vincular al estudiante con el entorno económico de Pucón, dentro del que destaca el programa Escuela empresa, el cual busca instalar competencias en el estudiante que le permitan reconocer en el territorio local posibilidades de negocio a través de sesiones de trabajo con empresarios locales (Municipalidad de Pucón 2010c). El sujeto que se asocia a este atractivo es 
el sujeto joven (Cuadro 3), cuya participación en la comunicación turística local no se restringe por criterios socio-espaciales.

Hoy estamos enseñándole al niño que, producto de que vive en una ciudad turística, debe cuidar el entorno, y que eso a futuro le puede servir como recurso económico. En otras palabras, estamos tratando de que este niño sea consciente de que vive dentro de una ciudad turística, en un ambiente turístico, por lo tanto, debe tener un especial cuidado respecto del tema ambiental. (Funcionario municipal 4)

La educación turística es quizás el mecanismo más claramente identificable con la posibilidad de inclusión en el Pucón turístico. Ella está planificada de modo tal que, desde la educación básica hasta la educación superior, se estimula a los educandos a formar parte de la estructura turística comunal a través de una carrera técnico-profesional. Así, la población segregada observada desde el atractivo servicio turístico profesionalizado aparecería incluida en el modelo de desarrollo territorial en tanto sujetos susceptibles de incluirse en un plan educativo turístico.

\section{ATRACTIVO TURISMO DE LUJO}

Este atractivo tributa a la representación del perfil social al que apunta el turismo local. La posibilidad de atraer a público de alto poder adquisitivo se corresponde con servicios que exaltan la figura de una ciudad que ofrece turismo de elite (Municipalidad de Pucón 2011b: 4). El asentamiento urbano segregado se situaría en las antípodas de este atractivo toda vez que la pobreza sería incompatible con el Pucón turístico:

En las poblaciones periféricas como Los Arrayanes y Cordillera, la mayoría de la gente que vive allí proviene del sector rural. La mayoría de estas personas proviene de niveles socioeconómicos vulnerables, trabajan por el sueldo mínimo. (Funcionario municipal 5)

El gobierno comunal posee un rol más bien marginal en este atractivo, dejando su tratamiento y regulación en manos de la empresa privada. Sumada a su función interventora, además se espera del sujeto empresario una directa conexión productiva con la población local. Con todo, se observa que para el gobierno comunal de Pucón es el empresario el sujeto que debe liderar el desarrollo de la industria turística local por medio de sus planes de negocios: "Su fuerza empresarial será asociada y 
competitiva, integrará a la comunidad, permitiéndole al turismo consolidarse como la actividad primordial de la comuna y en la principal fuente de empleo e ingresos de la comuna" (Municipalidad de Pucón 2011b: 3)

Desde la perspectiva del gobierno comunal, el rol del empresariado local está muy fuertemente sedimentado respecto de la conversión productiva del territorio. De hecho, es precisamente la empresa privada el sector que mayor ingreso anual genera al municipio, el que equivale a un 30\% del total (Municipalidad de Pucón 2012, 2011a).

El aporte que el Casino [de Juegos] hace al presupuesto municipal es esencial. Sin esos aportes nosotros tendríamos que retroceder en varias unidades, como Aseo y Ornato, como Alumbrado Público, Seguridad Ciudadana, en Medio ambiente. Por lo tanto, sería una catástrofe que Pucón dejara de percibir sus recursos. El Casino para nosotros es esencial. (Funcionario municipal 2)

Siguiendo este primado, el gobierno comunal busca instalar el emprendimiento en la población bajo criterios propios de la empresa privada. Es así que en el año 2009 se crea el Centro Empresarial Municipal, cuyo objetivo es "vincular y apoyar al microempresario local con los distintos actores que intervienen en el desarrollo de la actividad empresarial" (Municipalidad de Pucón 2010b, 154). Se busca instalar el emprendimiento en la población como una forma de reducir brechas económicas y participar directamente en la construcción de la imagen de destino turístico.

El ciudadano típico de Pucón es aquel que tiene su vivienda propia, que ya hizo los esfuerzos para construir una segunda vivienda tipo cabaña para arrendarla en el verano. En paralelo, al menos una persona de ese hogar trabaja en la industria del rubro hotelero ya sea como garzón, como barman, mucama en alguno de los hoteles que están distribuidos; y ocasionalmente el jefe de familia está ligado a la artesanía. (Funcionario municipal 3)

La lógica estaría situada en que sólo como sujeto empresario se puede intervenir y participar en el tratamiento del perfil socioeconómico al cual apuntan los bienes y servicios propios de la industria turística local. Por ello, frente a la exclusión del asentamiento urbano segregado en la comunicación del atractivo turismo de lujo, el gobierno comunal apuesta por conectar las economías familiares con los planes de negocio locales o bien por convertir a la población local en sujeto empresario: "Lo que queremos es que el puconino tipo pueda emprender, pueda tener una 
mejor calidad de vida a través de la industria del turismo" (Funcionario municipal 6).

Se obtiene pues que, observado desde el atractivo turismo de lujo, el asentamiento urbano segregado es incluido en el modelo de desarrollo territorial en tanto sujetos susceptibles a integrarse a la fuerza laboral local o bien a transformarse en emprendedores o empresarios.

\section{ATRACTIVO CULTURA}

No obstante, el patrimonio arquitectónico de la urbe comunal y de la huella cultural dejada por los colonos europeos de principios del siglo XX, el atractivo cultural al cual apuntan los más recientes esfuerzos comunales en materia de innovación turística se sitúa en el pueblo mapuche (Municipalidad de Pucón 2010a). El atractivo cultural mapuche se comunica mediante la idea de tradición ancestral, congregación ritual y como estilo de vida superviviente contenido en la ruralidad:

El turismo étnico hoy día está presente a la oferta turística de Pucón. Tenemos localidades en donde las comunidades ya están integradas a la oferta turística, y van a continuar siendo apoyadas a través del municipio [...] creo que en los próximos diez años ellos se van a incorporar totalmente a la oferta turística. (Funcionario municipal 2)

Como es de suponer, el asentamiento urbano segregado se escinde de estas particulares evocaciones culturales. En términos de imagen, este es observado como área de pobreza urbana homogénea y concentrada, cuyo tratamiento se sostendría exclusivamente en la política social dirigida por el gobierno comunal, obteniéndose desde allí un grupo social caracterizado en su precariedad y habituado al estímulo municipal, cuyas prácticas, problemas, necesidades y estilos de vida se trivializan precisamente en torno a la política social:

Somos una comuna emergente, una comuna en vías de desarrollo, una comuna que va a lograr pleno éxito en su crecimiento. Pero también hay sectores vulnerables que son atendidos con las ganancias que obtenemos con el turismo. (Funcionario municipal 3)

El asentamiento urbano segregado observado desde el atractivo cultura no ofrece elementos distintivos más allá de los criterios que los 
definen como usuarios de la política social. En consecuencia, sus estilos de vida se enlazan bajo la forma de la necesidad.

CUADRO 4: ASENTAMIENTO URBANO SEGREGADO COMO LADO EXCLUIDO DEL ATRACTIVO

\begin{tabular}{|c|c|c|}
\hline Atractivo & $\begin{array}{c}\text { Asentamiento urbano } \\
\text { segregado }\end{array}$ & Mecanismo de inclusión \\
\hline Naturaleza & $\begin{array}{c}\text { Deterioro/preservación } \\
\text { ambiental }\end{array}$ & Ética turística \\
\hline Turismo de Lujo & Pobreza & $\begin{array}{c}\text { Emprendimiento - } \\
\text { empleabilidad }\end{array}$ \\
\hline $\begin{array}{c}\text { Servicio } \\
\text { profesionalizado }\end{array}$ & Educandos/no educandos & $\begin{array}{c}\text { Educación técnico- } \\
\text { profesional }\end{array}$ \\
\hline Cultura & Precariedad trivializada & Política social \\
\hline \multicolumn{3}{|c|}{ FuENTE: Elaboración propia } \\
\hline \multicolumn{2}{|c|}{}
\end{tabular}

Se obtiene del Cuadro 4 que, si bien el asentamiento urbano segregado no participa de la comunicación turística local, el gobierno comunal dispone de mecanismos para su inclusión en la semántica del desarrollo territorial. La ética turística, el emprendimiento económico, la educación turística y una política social que trivializa la pecariedad del residente segregado son los elementos que movilizan al asentamiento urbano segregado hacia la narrativa promisoria y comprensiva; es decir, son los elementos que lo incluyen en el modelo de desarrollo territorial local. Entonces, el poblador del margen urbano segregado tiene abierta la posibilidad de participar en la comunicación turística bajo el rol de emprendedor, residente joven o como miembro de la cultura mapuche. De ahí se desprende que la distinción hacia el asentamiento urbano segregado que se observa en la comunicación del desarrollo territorial local esté ligada a un rol pasivo en cuanto al quehacer turístico de la ciudad de Pucón, vale decir, un espacio sin atractivos y solo contenedor de eventuales 'sujetos del turismo' (Cuadro 3). El asentamiento urbano segregado, por ende, sería un beneficiario del modelo turístico local, pero en ningún caso su protagonista, pues ese rol quedaría reservado para los 'sujetos del turismo' (Cuadro 3). Se observa, pues, que la invisibilización de la comunicación turística hacia el margen urbano segregado de Pucón encuentra su fundamento en el enlace comunicativo de elementos y roles probabilizadores del viaje de ocio. Asimismo, la comunicación del desarrollo territorial cumple la función de incluir al margen urbano segregado en la forma de precariedad social susceptible de ser tratada a través de la bonanza económica del turismo local; es decir, se procesa su 
complejidad a través de referencias temporales de un futuro promisorio y comprensivo orientado por el medio turismo. Este último se incorpora como el dispositivo fundante en la comunicación de futuro propiciada en el seno del desarrollo territorial, comunicación donde tiene cabida justamente el espacio no atractivo. Pero no obstante la función promisoria y comprensiva del desarrollo territorial en Pucón, su particular identidad como destino turístico es incompatible con el margen urbano segregado (espacio no atractivo). Por ello, la particularidad de la segregación socioespacial en Pucón estaría dada por los estrechos marcos de referencia individual (Cuadro 3) que ofrece el modelo de desarrollo territorial, lo que finalmente implica una paradoja entre la identidad del destino turístico y el asentamiento urbano segregado.

\section{CONCLUSIÓN}

Este trabajo ha querido proponer un esquema de observación respecto de la segregación socio-espacial de la ciudad de Pucón, la que ha sido construida observando la función del turismo y de la semántica del desarrollo territorial. Se concluyó que, dada la articulación del medio turismo en torno a la generalización simbólica del atractivo turístico, el asentamiento urbano segregado no participa de su comunicación. No obstante, sí lo hace de la semántica del desarrollo, toda vez que esta posee características más bien totalizadoras con el territorio al no establecer criterios de exclusión específicos en su comunicación. En base a estas consideraciones teórico-conceptuales, se caracterizó el asentamiento urbano segregado de la ciudad de Pucón desde su modelo de desarrollo territorial, tomando como unidad de análisis al gobierno comunal. De ello se obtuvo que el asentamiento urbano segregado de Pucón es distinguido mediante una tensión gestada en el seno de la articulación de la semántica del desarrollo territorial a través del medio turismo.

Los atractivos de Pucón se forjaron de manera paulatina desde la década de 1930. En ella tuvo una particular importancia la Empresa de Ferrocarriles del Estado, dentro de cuyos principales hitos se encuentra la construcción del Gran Hotel Pucón y la edición de revistas especializadas en turismo que exaltaban las bondades geográficas de la zona. El turismo, además, actuó como mecanismo de reapropiación de la región de La Araucanía, rol que tuvo como principal antesala al fracaso productivo de la colonización europea en la región. Desde entonces hasta nuestros días se han podido identificar como atractivos ejes de la comunicación turística 
local a la naturaleza, al turismo de lujo, a la profesionalización del servicio turístico y a la cultura. Estos atractivos se asocian a ciertos sujetos que juegan un exclusivo rol en su tratamiento. A ellos les hemos denominado sujetos del turismo, por ser a través de quienes se orienta la comunicación turística incorporada al desarrollo territorial de Pucón. Los atractivos son los elementos que permiten continuar la comunicación turística local, y como tales, son además los puntales del modelo de desarrollo territorial de Pucón dentro del cual se ha determinado que el asentamiento urbano segregado representa la precariedad social y espacial de la ciudad. Para caracterizar su inclusión en este modelo el presente trabajo se ha enfocado en el lado excluido de los atractivos, pues, es allí donde es posible observar cómo opera la promesa y comprensión de futuro articulada a través del medio turismo. Así, se ha establecido a la ética turística, a la educación técnico-profesional, al emprendimiento y a la política social como los mecanismos por medio de los cuales el asentamiento urbano segregado es incluido en el modelo de desarrollo territorial.RM

\section{REFERENCIAS}

Arnold, M. (2008). Las organizaciones desde la teoría de los sistemas sociopoiéticos. Cinta de Moebio, 32, 90-108.

Aragón, M. (2013). Lo efímero y la ciudad turística. A propósito de los haceres y lugares del turismo en el espacio urbano. Diálogos Latinoamericanos, 21, 111-124.

Andersen, N. A. (2003). The Undecidability of Decision. Autopoietic Organization Yheory. Working Paper, 12.

Booth, R. \& Lavín, C. (2013). Un hotel para contener el sur. ARQ, 83, 56-61.

Booth, R. (2010). El paisaje aquí tiene un encanto fresco y poético. Las bellezas del sur de Chile y la construcción de la nación turística. Historia Iberoamericana, 3(1), 1032.

Boisier, S. (2007). América Latina en un medio siglo (1950/2000): El desarrollo, ¿Dónde estuvo? Investigaciones regionales, 1, 145-167.

Bengoa, J. (2000). Historia del pueblo mapuche. Siglo XIX y XX. Santiago de Chile: LOM.

Butler, R. \& Hinch, T. (2007). Introduction: Revisiting Common Ground. En R. Butler \& T. Hinch (Eds.), Tourism and Indigenous Peoples: Issues and Implications (pp. 112). Oxford: Butterworth Heinemann.

CEPAL (2014). Los pueblos indígenas en América Latina. Avances en el último decenio y retos pendientes para la garantía de sus derechos. Santiago de Chile: CEPAL.

Contreras, J. (2008). La infancia de Pucón. Pucón: Ilustre Municipalidad de Pucón.

Farías, I. (2008). Touring Berlin. Virtual destination, tourist communication and the multiply city. Tesis doctoral. Universidad de Humboldt. Berlín.

Geisse, G. \& Valdivia, M. (1978). Urbanización e industrialización en Chile. EURE 5(15), 11-35. 
Hidalgo, R. \& Zunino, H. (2012). Negocio inmobiliario y migración por estilo de vida en la Araucanía lacustre: La transformación del espacio habitado en Villarrica y Pucón. AUS, 11, 10-13.

Luhmann, N. (1991). Sistemas sociales: Lineamientos para una teoría general. México DF: Universidad Iberoamericana - Alianza.

Luhmann, N. (1997). Observaciones de la modernidad. Racionalidad y contingencia en la sociedad moderna. Barcelona: Paidós.

Luhmann, N. (2005). Organización y decisión. Autopoiesis, acción y entendimiento comunicativo. Barcelona: Anthropos.

Luhmann, N. (2007). La sociedad de la sociedad. México DF: Herder.

Luhmann, N. (2010). Organización y decisión. México DF: Herder.

Luhmann, N. (2013). La moral de la sociedad. Madrid: Trotta.

González, R. (2013). Revistando la historia de las teorías del desarrollo. CUHSO, 23(1), $55-91$.

Pinto, J. (2003) La formación del Estado y la nación, y el pueblo mapuche. De la inclusión a la exclusión. Santiago de Chile: DIBAM.

Spencer-Brown, G. (1972). Laws of the form. New York: The Julian Press.

Torres Nafarrate, J. (2009). Niklas Luhmann: La política como sistema. México DF: Universidad Iberoamericana.

Violá, A. (2000). Antropología del desarrollo. Teorías y estudios etnográficos en América Latina. Barcelona: Paidós.

Zúñiga, C. (2013). La explotación del bosque nativo en la zona de Villarrica. Una aproximación desde la historia oral. En C. Zúñiga (Comp.), Fragmentos de historia regional. La Araucanía en el siglo XX (pp. 159-200). Temuco: Universidad de la Frontera.

Zunino H., Hidalgo, R., \& Marquardt, E. (2011). Vivienda Social y segregación espacial en la ciudad de Pucón, Chile: Entre el enclaustramiento y la integración con el hábitat turístico. INVI, 26, 15-55.

\section{FUENTES DE INTERNET}

Bertin, X. (2013). Naturaleza Originaria será el sello de promoción de La Araucanía, Diario La Tercera, consultado el 20 de febrero de 2014 desde: http://diario.latercera.com/2013/04/28/01/contenido/pais/31-135625-9naturaleza-originaria-sera-el-sello-de-promocion-de-la-araucania.shtml

Empresa de Ferrocarriles del Estado (1934). Revista En Viaje, n ${ }^{\circ}$ 4, consultada el 08 de enero de 2014 desde: http://www.memoriachilena.cl/archivos2/pdfs/mc0028312.pdf

Empresa de Ferrocarriles del Estado (1940). Revista En Viaje, n 76, consultada el 08 de enero de 2014 desde: http://www.memoriachilena.cl/archivos2/pdfs/mc0014437.pdf

Gobierno de Chile (2011). Plan de Desarrollo Turístico de La Araucanía 2011 - 2014, consultado el 03 de noviembre de 2013 desde: http://araucania7.cl/plandesarrollo-turistico-araucania-2011-2014/

Gobierno de Chile (2010). Plan Araucanía 7, consultado el 08 de noviembre de 2013 desde: http://araucania7.cl/documento-plan-araucania-7/ 
Municipalidad de Pucón (2012). Cuenta Pública Municipal de Pucón año 2011, consultada el 21 de febrero de 2014 desde: http://www.municipalidadpucon.cl/index.php/cuenta-publica

Municipalidad de Pucón (2011a). Cuenta Pública Municipal de Pucón año 2010, consultada el 21 de febrero de 2014 desde: http://www.municipalidadpucon.cl/index.php/cuenta-publica

Municipalidad de Pucón (2011b). Plan de desarrollo turístico 2011 - 2014, consultado el 17 de noviembre de 2013 desde: http://www.municipalidadpucon.cl/web2010/transparencia/LetraC/PLADETUR2 $\underline{011}$

Municipalidad de Pucón (2010a). Plan de desarrollo comunal de Pucón 2010 - 2014, consultado el 21 de febrero de 2014 desde: http://www.municipalidadpucon.cl/index.php/pladeco

Municipalidad de Pucón (2010b). Cuenta Pública Municipalidad de Pucón año 2009, consultada el 21 de febrero de 2014 desde: http://www.municipalidadpucon.cl/index.php/cuenta-publica

Municipalidad de Pucón (2010c). Plan anual educativo municipal 2010, consulado el 21 de febrero de 2014 desde: http://www.municipalidadpucon.cl/index.php/documentos-publicosmunicipalidad/150-plan-anual-de-desarrollo-educativo-municipal

SOBRE EL AUTOR

Patricio Espinosa es Antropólogo por la Universidad Católica de Temuco y Magíster en Análisis Sistémico Aplicado a la Sociedad por la Universidad de Chile. Actualmente se desempeña como académico en el Departamento de Antropología de la Universidad Católica de Temuco, Chile. Entre sus últimas publicaciones destacan: La lectura del significado: desafíos en la intervención de lo social (junto a Nury Espinosa, Santiago de Chile, 2015), y La prevención del consumo de drogas en el sistema educativo chileno: SENDA y la Escuela (MAD, 2014)

\section{CONTACTO}

Departamento de Antropología

Facultad de Ciencias Sociales, Universidad Católica de Temuco

Manuel Montt 56, Edificio C.

Fono: 045-2-205309

pespinosa@educa.uct.cl

Recibido: Octubre 2015

Aceptado: Marzo 2016 